\title{
Will Consolidation of Primary Care Into Hospital Systems Spell Doom for the Patient- Centered Medical Home and the US Health Care System?
}

James M. Gill, MD, MPH

(Fam Med. 2018;50(3):176-8.)

doi: 10.22454/FamMed.2018.989867

$\mathrm{t}$ is widely known that the US health care system has high cost and poor outcomes compared to other developed countries, ${ }^{1}$ largely due to lack of a strong primary care system. ${ }^{2}$ The Joint Principles of the PatientCentered Medical Home (PCMH) was developed in 2007 as a strategy to address this problem. ${ }^{3}$ The PCMH can be summarized as combining the basic principles of primary care with new ways of organizing and delivering care and increased reimbursement to support this new model of primary care. ${ }^{2}$ One of the key elements of the PCMH is having a physician-led team that coordinates each patient's care with the rest of the health care system. But given that primary care offices in the United States are increasingly becoming part of hospitals and other integrated health care systems, ${ }^{4}$ is the PCMH becoming obsolete? I would argue that not only is the PCMH still an essential component of achieving the triple aim both inside and outside of integrated health systems, but that it is also an important way to guard against the detrimental effects of too much consolidation of primary care practices into hospital systems.

Much of the evidence of benefit for the PCMH has come from large integrated health care systems. At Group Health Cooperative Puget Sound, the PCMH model improved quality of care as well as patient and provider satisfaction, and reduced emergency department
(ED) visits and hospital admissions. ${ }^{5}$ Similar improvements have been seen in the Veterans Administration system, ${ }^{6}$ Geisinger Health System in Pennsylvania, ${ }^{7}$ and other large integrated systems. ${ }^{8}$ Given the positive impact in large integrated health care systems, it would seem that the PCMH model of care is still relevant in that context. But since large health care systems rely on their primary care practices for referrals to their more lucrative specialty and hospital services, one could surmise that the PCMH might not achieve its greatest benefit in these systems. In fact, the greatest potential benefit for the PCMH is in small independent practices.

Studies of the PCMH in independent practice have been more mixed. One study of these practices in southeastern Pennsylvania found improvements in diabetes, ${ }^{9}$ but a more recent study exploring a wider set of outcomes in the same regional PCMH program found few positive results. ${ }^{10}$ And a study of five PCMH practices in Rhode Island found significant reductions for avoidable ED visits, but not for other hospital utilization or for diabetes and preventive care. ${ }^{11}$

These results might seem surprising, since one of the hallmarks of the PCMH is to coordinate primary care with the rest of the health

From Delaware Valley Outcomes Research, Newark, DE 
care system, which one might imagine to be more important in smaller independent practices where primary care is not part of that larger health care system. There are several reasons why studies have not shown more robust outcomes in small practices. The first reason relates to how the PCMH is measured. Most PCMH programs require that practices be certified as a PCMH by the National Center for Quality Assurance (NCQA) in order to be counted as a PCMH and receive PCMH reimbursement. However, the NCQA tool is not a particularly good measure of "PCMH-ness." ${ }^{2}$ It focuses heavily on the technical components of the PCMH, with little focus on the core components of primary care. It is these core components (such as continuity of care) that lead to reductions in hospital services. ${ }^{13,14}$ In particular it is the interpersonal continuity with an individual physician that patients value ${ }^{15}$ and that leads to trust in that physician. ${ }^{16}$

While NCQA certification misses many of these important components of the PCMH, it requires checking the boxes for dozens of technical items such as use of information technology, which has questionable impact on quality and outcomes. ${ }^{17}$ These requirements divert time and resources from the more important components of the PCMH and from the personal attention that patients value. When combined with the payment required for NCQA certification, this results in small independent practices being less likely to be designated as a $\mathrm{PCMH},{ }^{18}$ even though they may adhere to the principles of the PCMH as much as or more than practices in large integrated systems.

Another reason for the suboptimal impact of the PCMH in small independent practices is suboptimal reimbursement. Transforming primary care to a PCMH model requires significant additional costs for practices..$^{19} \mathrm{~A}$ study by the Commonwealth Fund estimated the cost of PCMH activities at over $\$ 500,000$ per full-time physician, with an annual cost that translates to $\$ 16-\$ 17$ per patient per month (PPPM). ${ }^{20}$ More recent studies have found similar costs. ${ }^{21}$ Most payers do not come close to this when reimbursing for PCMH activities, making it difficult to make the changes necessary to improve outcomes. Furthermore, payments are often not sustained over a long enough period of time to improve outcomes. In my state of Delaware, the state Blue Cross program collaborated with the state medical society on a statewide PCMH program that initially paid $20 \%$ higher rates for practices to build a
PCMH model, with 25\%-30\% higher rates once PCMH certification was achieved. However, this program was disbanded after 3 years, being replaced by a program that pays an average of $\$ 2.50$ PPPM for care coordination-far too low for meaningful care coordination. While the program does offer additional payments for achieving quality measures and/or reductions in hospital utilization, these payments require significant additional work for practices to document quality measures of questionable value, on top of the large administrative burden that was required for the previous NCQA certification. And these payments are not guaranteed, usually falling far short of what is promised by the payer. Such at-risk payments are not sufficient and reliable enough to sustain the PCMH model in small independent practices, ${ }^{22}$ and have prompted some to prophesy the impending death of the PCMH. ${ }^{23}$

If this trend of inadequate payment or unstable payments continues, it may be true that the PCMH model cannot be sustained in the United States, at least for small independent practices. This could spell doom not only for the PCMH but for the US health care system. Studies have shown hospital-owned practices have significantly higher costs than independent practices and that large practices have higher costs than smaller practices. ${ }^{24}$ Other studies have found smaller practices to have advantages in quality and utilization, including fewer preventable admissions. ${ }^{25}$ One reason is that small, physician-owned practices can provide a greater level of personalization and responsiveness to patient needs. ${ }^{26}$ Continuing the trend of consolidating primary care practices into hospital systems is not a good thing for health care in the United States.

In order to save the US health care system, we need to reverse the trend of hospital consolidation by supporting small independent practices in their quest to transform and maintain a PCMH model of care. This can be done in the context of accountable care organizations (ACOs) for independent practices. ${ }^{26}$ These ACOs can be a mechanism for small independent practices to collectively develop and implement the PCMH model of care, and to pressure payers to provide the necessary reimbursement to fund this model of care. If ACOs cannot provide enough leverage, then this pressure can be applied by state governments that represent the patients who benefit from improved care. ${ }^{27}$

In summary, the PCMH is relevant in large integrated health systems, which now 
represent a significant proportion of primary care in the United States. But it is even more important for small independent practices, which represent the best hope for the United States to achieve the quadruple aim. ${ }^{28}$ To succeed in this goal, the PCMH needs to be fully funded by payers. While some may argue that paying extra for $\mathrm{PCMH}$ activities is not feasible in the era of cost containment, I would argue that what is not feasible is not investing in the PCMH. Even the higher estimate of \$16-\$17 PPPM represents only about $2.5 \%$ of the health care spend in the United States. Given that the United States spends double per person compared to other developed nations, this investment of $2.5 \%$ can result in a savings for nonprimary care services equaling many times that amount. If this level of investment by payers comes to fruition, the PCMH model can help primary care practices to improve quality and reduce costs. By supporting these small independent practices, the PCMH model can move the US health care system closer to the rest of the developed world, with primary care as the lynchpin of an effective and efficient health care system.

CORRESPONDENCE: Address correspondence to Dr Gill, Delaware Valley Outcomes Research, 17 Henderson Hill Rd, Newark, Delaware 19711. gillj@dvoresearh.com.

\section{References}

1. Davis K, Stremikis K, Squires D, Schoen C. Mirror, Mirror on the Wall: How the Performance of the US Health Care System Compares Internationally. The Commonwealth Fund. June 2014.

2. Landon BE, Gill JM, Antonelli RC, Rich EC. Prospects for rebuilding primary care using the patient-centered medical home. Health Aff (Millwood). 2010;29(5):827-834.

3. Robert Graham Center for Policy Studies in Family Medicine and Primary Care. The Patient Centered Medical Home: History, Seven Core Features, Evidence and Transformational Change. November, 2007.

4. Murphy B. For first time, physician practice owners are not the majority. AMA Wire. May 31, 2017. https://wire.amaassn.org/practice-management/first-time-physician-practiceowners-are-not-majority. Accessed January 24, 2018.

5. Reid RJ, Coleman K, Johnson EA, et al. The Group Health medical home at year two: cost savings, higher patient satisfaction, and less burnout for providers. Health Aff (Millwood). 2010;29(5):835-843.

6. Rosland AM, Nelson K, Sun H, et al. The patient-centered medical home in the Veterans Health Administration. Am J Manag Care. 2013;19(7):e263-e272.

7. Paulus RA, Davis K, Steele GD. Continuous innovation in health care: implications of the Geisinger experience. Health Aff (Millwood). 2008;27(5):1235-1245.

8. Nielsen M, Olayiwola JN, Grundy P, Grumbach K. The patient-centered medical home's impact on cost and quality: An annual update of the evidence, 2012-2013. Patient Centered Primary Care Collaborative. January 2014.
9. Gabbay RA, Bailit MH, Mauger DT, Wagner EH, Siminerio L. Multipayer patient-centered medical home implementation guided by the chronic care model. Jt Comm J Qual Patient Saf. 2011;37(6):265-273.

10. Friedberg MW, Schneider EC, Rosenthal MB, Volpp KG, Werner RM. Association between participation in a multipayer medical home intervention and changes in quality, utilization, and costs of care. JAMA. 2014;311(8):815-825.

11. Rosenthal MB, Friedberg MW, Singer SJ, Eastman D, Li Z, Schneider EC. Effect of a multipayer patient-centered medical home on health care utilization and quality: the Rhode Island chronic care sustainability initiative pilot program. JAMA Intern Med. 2013;173(20):1907-1913.

12. Stange KC, Nutting PA, Miller WL, et al. Defining and measuring the patient-centered medical home. J Gen Intern Med. 2010;25(6):601-612.

13. Gill JM, Mainous AG III. The role of provider continuity in preventing hospitalizations. Arch Fam Med. 1998;7(4):352357.

14. Gill JM, Mainous AG, Nsereko M. The effect of continuity of care on emergency department use. Arch Fam Med. 2000;9(4):333-338.

15. Saultz J, Albedaiwi W. Interpersonal Continuity of care and patient satisfaction: A critical review. Ann Fam Med. 2004;2(5):445-51.

16. Mainous Ar, Baker R, Love M, Gray D, Gill J. Continuity of care and trust in one's physician: evidence from primary care in the United States and the United Kingdom. Fam Med. 2001;33(1):22-27.

17. Gill JM, Chen YX, Glutting JJ, Diamond JJ, Lieberman MI. Impact of decision support in electronic medical records on lipid management in primary care. Popul Health Manag. 2009;12(5):221-226.

18. Raffoul M, Petterson S, Moore M, Bazemore A, Peterson L. Smaller Practices Are Less Likely to Report PCMH Certification. Am Fam Physician. 2015;91(7):440.

19. Gill JM, Bagley B. Practice transformation? Opportunities and costs for primary care practices. Ann Fam Med. 2013;11(3):202-205.

20. Zuckerman S, Merrell K, Berenson R, et al. Incremental Cost Estimates for the Patient-Centered Medical Home. The Commonwealth Fund; 2009.

21. Zimlich R. The costs of becoming patient centered. Medical Economics. May 25, 2013. http://medicaleconomics.modernmedicine.com/medical-economics/content/modernmedicine/ modern-medicine-feature-articles/costs-becoming-patient-cen Accessed November 17, 2017.

22. Sessums LL, Conway PH, Conway PH. Saving Primary Care. JAMA Intern Med. 2017;177(11):1560-1562.

23. Bujold E. The Impending Death of the Patient-Centered Medical Home. JAMA Intern Med. 2017;177(11):1559-1560.

24. Robinson JC, Miller K. Total expenditures per patient in hospital-owned and physician-owned physician organizations in California. JAMA. 2014;312(16):1663-1669.

25. Casalino LP, Pesko MF, Ryan AM, et al. Small primary care physician practices have low rates of preventable hospital admissions. Health Aff (Millwood). 2014;33(9):1680-1688.

26. Mostashari F. The Paradox of Size: How Small, Independent Practices Can Thrive in Value-Based Care. Ann Fam Med. 2016;14(1):5-7.

27. Koller CF, Khullar D. Primary Care Spending Rate - A Lever for Encouraging Investment in Primary Care. N Engl J Med. 2017;377(18):1709-1711.

28. Bodenheimer T, Sinsky C. From triple to quadruple aim: care of the patient requires care of the provider. Ann Fam Med. 2014;12(6):573-576. 